\title{
So What, It's Only a Five Percent Inflation
}

\author{
LEONALL C. ANDERSEN
}

Is

$\mathrm{N}$ recent years there has been an apparent willingness on the part of many individuals to accept the present five percent rate of inflation as a more or less permanent feature of our economy. This view may be exemplified by the expression "So what, it's only a five percent inflation."

Some individuals argue that a five percent rate of inflation is relatively satisfactory when compared with the recent double-digit rate or with the higher rates of inflation in most other countries. Others argue that, it inflation is stabilized at this rate, individuals would take actions in the market place such that their money income would also rise at a five percent annual rate. Consequently, a permanent five percent rate of inflation would have little effect over time on the ability of individuals to buy goods and services.

But such is not the case. Even if an individual's money income rises as fast as the rate of inflation and his real income received (actual purchasing power) thus remains unchanged, his after tax real income decreases. The reason for this result is the progressive nature of the existing personal income tax structure which causes an individual's tax payments to rise faster than money income.

Indexation of the Federal personal income tax structure - altering the structure each year according to the rate of inflation that has been experienced - is a prominently mentioned method for preventing such a decrease in after tax real income. Indexation for inflation would maintain the degree of progression provided in the existing personal income tax structure, but progression would be based on real income received instead of money income. With such a program, tax payments as percent of income would increase only when a worker receives a real wage rate increase (purchasing power of money wage rate) for a given job, or moves into a job paying a higher real wage rate. Effective tax rates would not rise as in the case where wages were rising because of the pernicious effects of inflation.

This article illustrates the impact of the 1976 personal income tax structure on after tax real income during a prolonged period of five percent inflation. The example used is that of a worker currently holding a job paying $\$ 3.00$ an hour and a worker holding the same job at a later date. Income taxes are calculated for a married couple who have two dependent children, take the standard deduction, and file a joint return. The article also presents the changes in the parts of the 1976 personal income tax structure applicable to this worker if there were indexation for the rate of inflation. ${ }^{1}$

\section{WWACT OP TIE 1976 PDSONAL INOME TA STITUTURE}

The effect of inflation on after tax real income can be illustrated by three simple examples - a 5 percent rate of inflation and no growth in real income, a 3.5 percent rate of growth in real income and no inflation, and both a 5 percent inflation and a 3.5 percent rate of growth in real income. The time period considered is the next 45 years, the expected number of remaining years of work for a twenty year old worker.

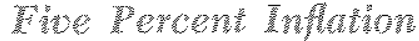

In this case, it is assumed that the money wage rate for this job increases over the next 45 years at the same rate as inflation; thus, there is no increase in the real wage rate. Table $I$ presents the implications for

1 Other provisions would also be indexed, but they are not considered in this article. 


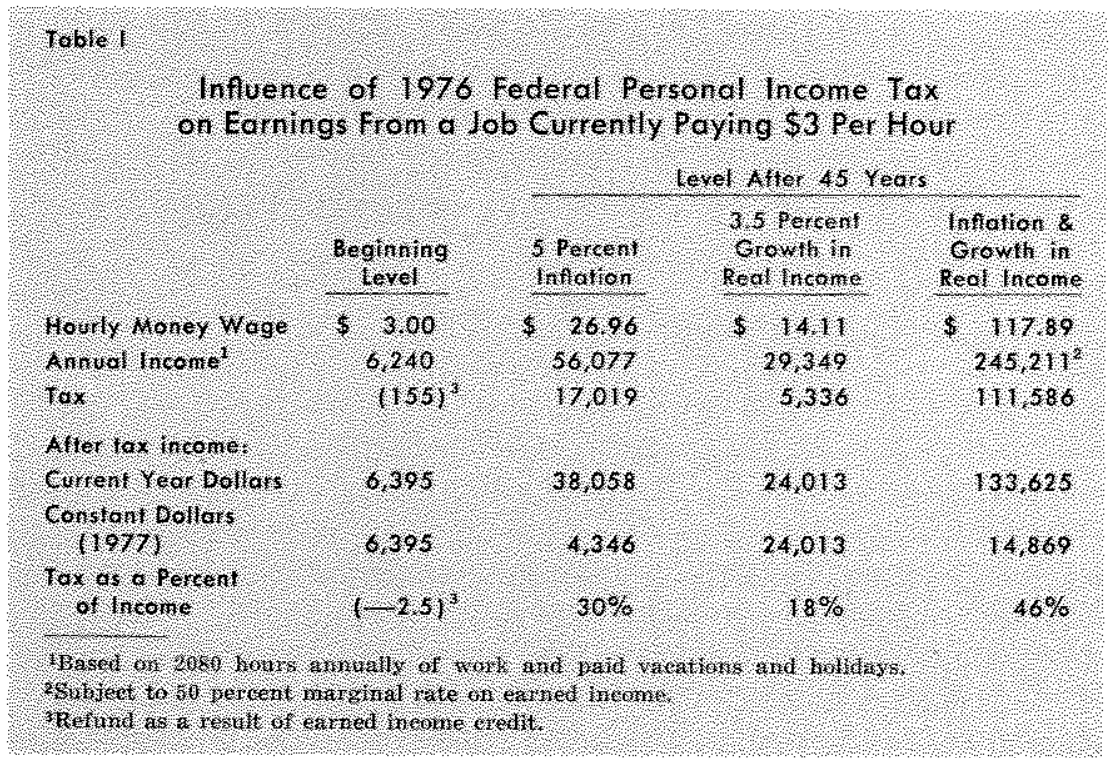

would be considerably less. This result is accounted for by the rise in taxes as a percent of income shown in the table, but this is the normal result of the progression provided in the existing personal income tax structure.

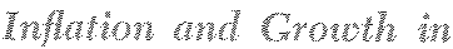 Ped Treome}

A more realistic assumption is that the money wage rate for this job rises at a rate reflecting both the rate of inflation and the increase in productivity (the real wage rate). In this case it is assumed that the money wage rate increases at an 8.5 percent annual rate the sum of the assumed 5 percent rate of inflation and a 3.5 percent rate of after tax real income and for taxes as at percent of income.

The money wage rate would increase from $\$ 3$ to $\$ 27$ per hour (Table I), and annual money income received would increase from $\$ 6,240$ to $\$ 56,077 *^{2}$ Nevertheless, as a result of inflation the higher money income received 45 years from now would purchase only the same amount of goods and services as in 1977. On average, the prices of most items purchased would rise as much as money income. Exhibit I presents the prices of selected items at the end of the period, assuming that all prices increase at the same rate as inflation.

Although real income received by a person holding this job remains unchanged, after tax real income decreases from $\$ 6,395$ to $\$ 4,346$. The reason for this result is the progressive nature of the existing personal income tax structure in which taxes as a percent of income received rises from -2.5 percent to 30 percent. $^{3}$

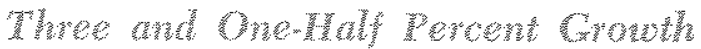

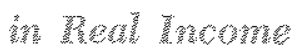

This case assumes that the money wage rate of a worker holding this job and, hence, the real wage rate, increases at a 3.5 percent annual rate. Table I indicates that, while money income would increase from $\$ 6,240$ to $\$ 29,349$, the increase in after tax real income

\footnotetext{
'Based on pay for 2080 hours of work, paid vacation, and holidays.

The -2.5 percent figure results from the 1976 provision for an earned income credit for low income families with dependent children.
} growth in productivity (that is, the real wage rate).

According to Table $\mathrm{I}$, the level of after tax real income of a worker holding this job would be $\$ 14,869$ compared with $\$ 24,013$ in the previous case, even though the real wage rate rose the same in each case. Also, taxes as a percent of income are 46 percent com-

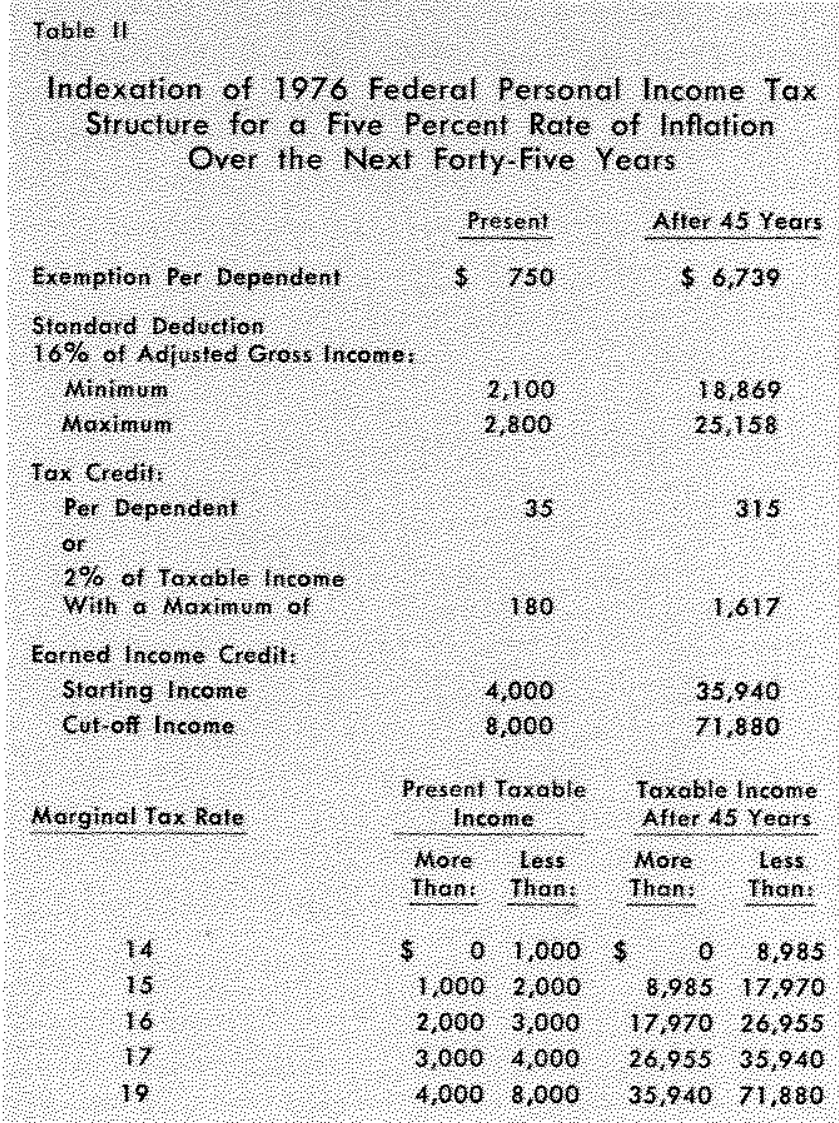

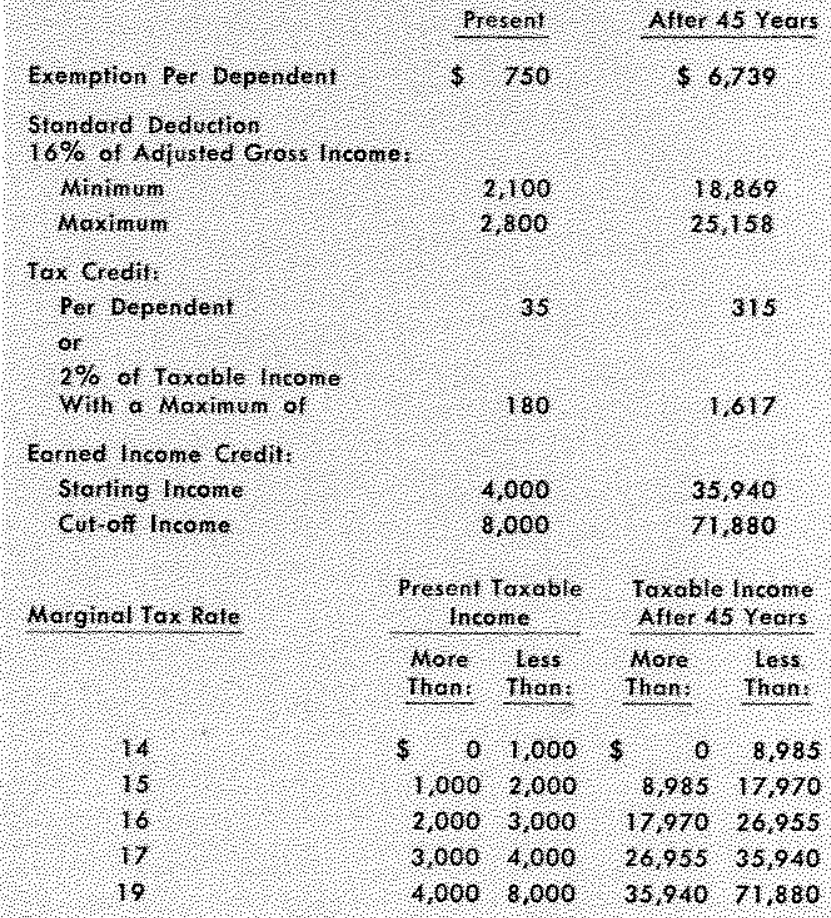


pared with 18 percent. The increase in tax burden reflects the effect of inflation transferring resources from the taxpayer to the government under the existing personal income tax structure.

\section{WDDEA

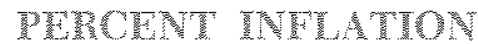

Table II presents the provisions of the 1976 personal income tax structure applicable to the worker at the beginning of the period and these same provisions at the end of 45 years if they were indexed for a 5 percent rate of inflation. Such indexation would maintain the tax payment of a worker holding the assumed job as a percent of income received at the same level as in 1977 in the case of inflation and no growth in real income, and at the level implied at the end of 45 years in the case of growth in real income without inflation.

The table indicates that substantial changes in the tax provisions would be required to accomplish these results. For example, the exemption per dependent would be $\$ 6,739$ and the minimum standard deduction $\$ 18,869$. The lowest marginal tax rate would apply to taxable income up to $\$ 8,985$.

\section{CORCITSTONS}

The simple examples considered here give results that may appear to be extreme. But that is the point. Acceptance of the view - "So what, its only a five percent rate of inflation " - because it is believed that individuals can take actions in the market place to protect their real income fails to take into consideration the existing personal income tax structure. Even if increases in an individual's money income reflect fully the rate of inflation, the gap between real income and after tax real income tends to widen. The reason for this result is that taxes as a percent of income increases as money income incorporates the rate of inflation.

Indexation of the existing personal income tax structure for the rate of inflation would eliminate the wid-

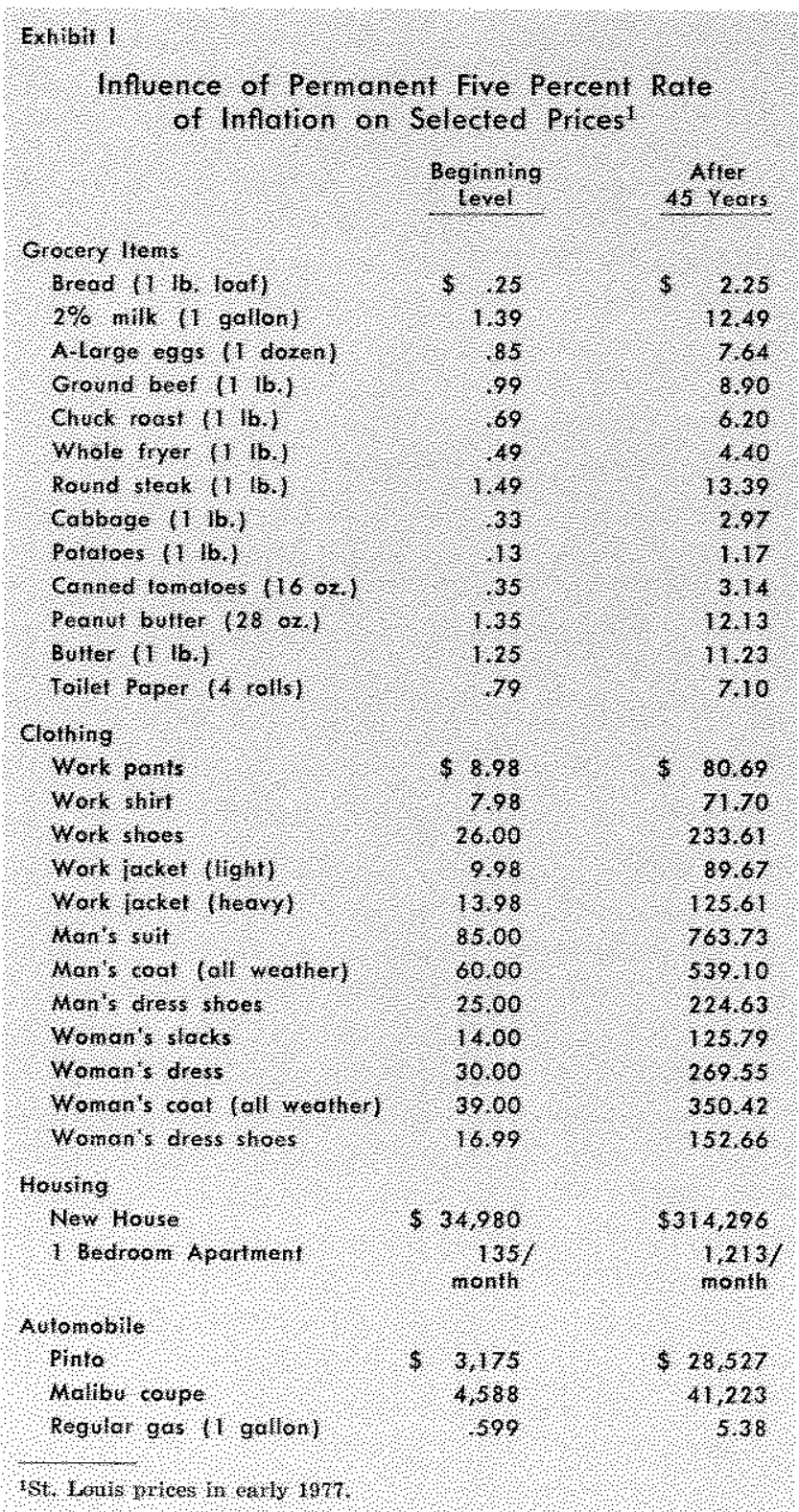

ening of the gap between real income received and after tax real income. There is also another method available for accomplishing the same objective. That method is the elimination of inflation by reducing the present excessive rate of monetary expansion.

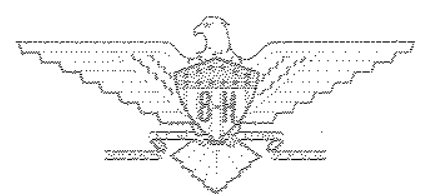

